\title{
Neighborhood phylodiversity affects plant performance
}

\author{
Juan Pablo Castillo, ${ }^{1}$ Miguel Verdú, ${ }^{2}$ and Alfonso Valiente-Banuet ${ }^{1,3,4}$ \\ ${ }^{1}$ Departamento de Ecología de la Biodiversidad, Instituto de Ecología, Universidad Nacional Autónoma de México, A.P. 70-275, \\ C.P. 04510, México, D.F., Mexico \\ ${ }^{2}$ Centro de Investigaciones sobre Desertificación (CIDE, CSIC-UV-GV), Camí de la Marjal s/n Apartado Oficial, 46470 Albal, \\ Valencia, Spain \\ ${ }^{3}$ Centro de Ciencias de la Complejidad, Ciudad Universitaria, Universidad Nacional Autónoma de México, 04510, \\ México, D.F., Mexico
}

\begin{abstract}
Facilitation and competition are ecological interactions that are crucial for the organization of plant communities. Facilitative interactions tend to occur among distantly related species, while the strength of competition tends to decrease with phylogenetic distance. The balance between both types of interactions will ultimately determine the specific composition of multispecies associations. Although multispecies patches are the arena in which coexistence develops among different phylogenetic groups within communities, the specific processes that occur across life stages have not been explored. Here we study how different species, in composing discrete patches in central Mexico, exert competitive or facilitative effects on seeds and seedlings. We relate these interactions to phylogenetic relationships among nurse species and beneficiary species, and among members of the patches. Survivorship and growth rates of the columnar cactus Neobuxbaumia mezcalaensis were highly positively related to increasing phylogenetic distance to different nurse species, to the presence of related species in patches, and to mean phylogenetic distances to the rest of the species in the patch. Each of these three elements influenced $N$. mezcalaensis differently, with different nurse species varying substantially in their early effects on emergence, and the nearest relatives and species composition of patches varying in their late effects on survival and growth. Our results emphasize that evolutionary relationships among co-occurring species in vegetation clumps exert direct and indirect effects on plants, affecting individual performance and species coexistence.
\end{abstract}

Key words: columnar cactus; community ecology; competition; facilitation; Neobuxbaumia mezcalaensis; nurse species; phylogenetic diversity; plant performance; Puebla, Mexico.

\section{INTRODUCTION}

During the last decade, the merging of phylogenetic biology and community ecology has provided ecologists with a novel and powerful framework to test hypotheses for community organization and to simultaneously consider broad temporal and spatial scales (Webb et al. 2002, Emerson and Gillespie 2008, Cavender-Bares et al. 2009). Many of these studies have used the phylogenetic relatedness of the interacting organisms and information about trait evolution to understand community assembly. Most studies have emphasized habitat filtering and competitive exclusion (e.g., Webb 2000, Cavender-Bares et al. 2004). For example, if traits are evolutionarily conserved and habitat filtering is the main assembly rule, closely related species should share similar environmental requirements and therefore will co-occur. In contrast, if ecological similarity among closely related species leads to strong competitive interactions, then phylogenetic overdispersion would be predicted (Webb et al. 2002). However, recent studies

Manuscript received 8 April 2010; accepted 14 April 2010. Corresponding Editor: J. Weiner.

${ }^{4}$ Corresponding author. E-mail: avalib@gmail.com show that facilitative processes can be crucial for the organization of many plant communities, and in these cases the establishment of many species is enhanced by nurse plants (Callaway 2007). These studies are increasingly evaluating the relative importance of facilitation and competition in structuring communities based on null model analyses of co-occurrence patterns (e.g., Dullinger et al. 2007, Maestre et al. 2008).

Facilitative associations have been shown to occur among distantly related species, leading to an overdispersed phylogenetic pattern (Valiente-Banuet and Verdú 2007, Verdú et al. 2009). In this case, contrary to competition in which species are spatially distributed in a checkerboard pattern, facilitation results in strong spatial associations. Surprisingly, high proportions of these early associations are maintained through the ontogenetic development of the interactions, until they reach the adult stage (Valiente-Banuet and Verdú 2008). This suggests long-term maintenance of positive interactions among distantly related phylogenetic groups (Prentice and Werger 1985, Couteron and Kokou 1997, Eccles et al. 1999). For logistical reasons, most experimental studies of facilitation have focused on pairwise interactions (Choler et al. 2001, Goldberg et al. 
2001, Callaway et al. 2002, 2005), but complex spatial relationships in patches, despite how common they are in nature, have been overlooked in most plant-plant facilitative studies.

We propose that an ubiquitous phenomenon in many ecosystems is discrete vegetation patches surrounded by open space that constitute the arena in which new individuals belonging to different species arrive via seed dispersal. Species coexistence ultimately will be determined by how the performance of the newcomers is affected by the interactions with the established species in the vegetation patch. In this context, studies at the scale of multispecies patches provide an opportunity to study interactions with communities rather than among selected constituents.

Within patches, established species may exert different effects on other species arriving as seeds, depending on the phylogenetic relationships between these species. Thus, neighbor effects can be envisioned as those exerted by the dominant species in the patch (nurse species), by the presence of nearest relatives, as well as the combined effect of all of the co-occurring species. More explicitly, and following our previous findings on the phylogenetic signatures left by facilitation and competition (Valiente-Banuet and Verdú 2007, 2008, Verdú and Valiente-Banuet 2008, Verdú et al. 2009), we expect distantly related species to exert early positive or facilitative effects on the performance of arriving taxa. We also expect that distantly related species should have smaller negative or competitive effects on the arriving taxa.

Increasing evidence exists that phylogenetic distance among competitors is a good predictor of seedling mortality rates that can ultimately explain species coexistence in a community (Webb et al. 2006, Bagchi et al. 2010). However, attempts to explain species coexistence must integrate the effects of neighbors across multiple life stages (Comita and Hubbell 2009). To introduce the effect of phylogenetic diversity of neighbors (neighborhood phylodiversity, hereafter) on the performance of the columnar cactus Neobuxbaumia mezcalaensis, we conducted seeding experiments in 31 vegetation patches that differed substantially in phylogenetic diversity. To encompass an extended period of the ontogeny of the interaction across multiple life stages between this columnar cactus and the vegetation patches, we monitored survivorship and growth rates of 440 individuals of different height in 181 patches for three years. Our analyses considered the relationships established within each patch between these demographic parameters of N. mezcalaensis and (1) its phylogenetic distance to the dominant nurse $\left(\mathrm{PD}_{\text {nur }}\right)$, (2) its phylogenetic distance to its nearest relative $\left(\mathrm{PD}_{\mathrm{rel}}\right)$, and (3) the effect of the mean phylogenetic distance of the focal plant with all the other species inhabiting the patch $\left(\mathrm{PD}_{\text {pat }}\right)$. We fitted generalized linear models between $\mathrm{PD}_{\text {nur }}, \mathrm{PD}_{\text {rel }}$, and $\mathrm{PD}_{\text {pat }}$ as independent variables and different $N$. mezcalaensis performance components (emergence, survivorship, and growth). By doing this we showed that survivorship and growth rates are highly sensitive to increasing $\mathrm{PD}_{\text {nur }}, \mathrm{PD}_{\text {rel }}$, and $\mathrm{PD}_{\text {pat }}$, but that the relative importance of these factors changes with the ontogeny of $N$. mezcalaensis.

\section{Materials and Methods}

Study area and species

The study was conducted between March 2005 and August 2008 in the semiarid Zapotitlán Salinas Valley in the state of Puebla, Mexico $\left(18^{\circ} 20^{\prime} \mathrm{N}, 97^{\circ} 28^{\prime} \mathrm{W}\right)$. Specifically, the site is located in the vicinity of the town of San Juan Raya at $1700 \mathrm{~m}$ altitude. The annual mean temperature is $21^{\circ} \mathrm{C}$ and annual rainfall averages $\sim 380$ $\mathrm{mm}$, with $85 \%$ of it falling during the summer (ValienteBanuet et al. 2000). The vegetation is dominated by the columnar cactus Neobuxbaumia mezcalaensis, which can reach densities of 1200 individuals $>1 \mathrm{~m}$ tall per hectare. There are many shrub species, including Lippia graveolens, Calliandra eriophylla, Mascagnia seleriana, Echinopteryx eglandulosa, Pseudosmodyngium multifolium, Acacia subangulata, A. constricta, Hechtia podantha, Cnidosculus tehuacanesis, Yucca periculosa, and Mimosa lacerata, that occur primarily in patches constituted by a variable number of species (Valiente-Banuet et al. 2000) (see Plate 1).

A patch was defined as a discrete group of plants growing together and surrounded by open space. Patch areas ranged from less than $1 \mathrm{~m}^{2}$ to $\sim 5 \mathrm{~m}^{2}$ (see photographs in Appendix A). Although highly variable in species composition, patches are usually dominated by one species that presents the highest biomass (the "nurse species"), and it appears that this nurse species may have facilitated the establishment of the subdominant species (see Archer et al. 1988). Recruitment of other species occurs beneath the canopies of the dominant and subdominant species and very rarely in the open (Valiente-Banuet and Verdú 2007).

Neobuxbaumia mezcalaensis is an unramified columnar cactus endemic to central Mexico, up to $12 \mathrm{~m}$ in height and 20-30 cm in diameter (Bravo-Hollis 1991). Flowering and fruiting seasons are from April to June, with an androdioecious reproductive system characterized by the presence of individuals with male or hermaphroditic flowers (Valiente-Banuet et al. 1997). Fruits growing along the ribs on the side of the plant (35 \pm 18 flowers/plant; mean \pm SE) are dehiscent and open during the night, exposing a sugary whitish pulp. On average, there are $302 \pm 16.85$ seeds/fruit (mean \pm SE; seeds $\sim 2 \mathrm{~mm}$ diameter). Bats and birds distribute seeds within patches of other species in a density ranging between 796 and 8570 seeds $/ \mathrm{m}^{2}$ (J. P. Castillo and A. Valiente-Banuet, unpublished data). This cactus recruits only through facilitation: although germination may take place in open spaces in very low percentages $(<1 \%)$, seedlings cannot survive for more than a month after seeding (Valiente-Banuet and Verdú 2007, Castillo and Valiente-Banuet 2010). 


\section{Patch characterization and phylogenetic distance calculations}

The effects of phylogenetic diversity of the neighborhood on $N$. mezcalaensis establishment, survivorship, and growth after three years were evaluated experimentally in 31 vegetation patches. These patches were randomly selected from a total of 904 patches that were previously sampled to obtain the frequency distribution of phylogenetic distances (1) between $N$. mezcalaensis and the species with the highest biomass in the patch (nurse species) and (2) between $N$. mezcalaensis and its nearest relative in the patch. The phylogenetic distance of $N$. mezcalaensis to the nurse species $\left(\mathrm{PD}_{\text {nur }}\right)$, to the nearest relative $\left(\mathrm{PD}_{\text {rel }}\right)$, and the mean phylogenetic distance $\left(\mathrm{PD}_{\text {pat }}\right)$ between $N$. mezcalaensis and the different species in each patch were obtained from the matrix of phylogenetic distances between all of the species and $N$. mezcalaensis. The phylogenetic distance matrix was obtained from the community phylogeny generated with the help of the program Phylocom 3.41 (Webb et al. 2008). This program generates a community phylogeny by matching the family names of our study species with those contained in a backbone phylogeny, which is the megatree based on the work of the Angiosperm Phylogeny Group (Stevens 2005). Because the megatree is calibrated with age estimates from Wikstrom et al. (2001), the program returns a calibrated tree with the study species in which the undated nodes have been evenly distributed between dated nodes and between dated nodes and terminals (Webb et al. 2008).

\section{Experiments on neighborhood effects on seedling establishment, survivorship, and growth}

Experiments began in the 31 randomly selected patches at the end of the fruiting season of $N$. mezcalaensis, in the wet season between the months of June and July 2005. Seeds were randomly collected from ripe fruits obtained during 2005 from a total of 12 individuals. An establishment experiment was conducted in which each experimental unit consisted of $50 \mathrm{~N}$. mezcalaensis seeds sown in a $15 \times 10 \mathrm{~cm}$ plot within each of 31 different patches. This number of seeds represents a density of 3333 seeds $/ \mathrm{m}^{2}$, which is within the range of 796-8570 seeds arriving to $1-\mathrm{m}^{2}$ plots through seed dispersal by frugivores (J. P. Castillo and A. ValienteBanuet, unpublished data). For seeding we used a grid in which we placed the seeds separated each other by distances of $1.5-2.2 \mathrm{~cm}$ to avoid intraspecific effects. Experimental units were protected from predators using a wire net cage $(15 \times 10 \times 7 \mathrm{~cm})$ nailed to the ground. Invertebrates, mostly ants, were excluded using a chlorine-based insecticide powder. Seeds were monitored daily until seedling emergence. After seedling emergence, survivorship was monitored monthly for three years. At the end of the experiment, the height of all surviving individuals growing in different patches was measured with a calliper in order to quantify plant growth.

Monitoring of survival of young preestablished individuals

We also tagged and monitored the survivorship of 440 individuals that were naturally established in a total of 181vegetation patches. The height of the tagged individuals ranged from 3 to $12 \mathrm{~cm}$, corresponding approximately to a range of ages between 3 and 14 years (A. Valiente-Banuet, unpublished data). Seedling survival was measured three years after tagging.

\section{Data analyses}

Data analyses consisted of fitting generalized linear models between the logarithms of $\mathrm{PD}_{\text {nur }}, \mathrm{PD}_{\text {rel }}$, and $\mathrm{PD}_{\text {pat }}$ as independent variables, with dependent variables being establishment, survivorship, and growth of N. mezcalaensis.

The establishment and survivorship of each seedling were considered as binary responses and therefore the fitted models considered a binomial distribution of errors. Growth of each seedling was considered as a continuous variable and thus Gaussian distribution was considered after log-transformation. As $\mathrm{PD}_{\text {nur }}, \mathrm{PD}_{\text {rel }}$, and $\mathrm{PD}_{\text {pat }}$ are correlated, we selected a subset of these variables by examining the best of $n$-models based upon Akaike's information criterion (AIC). When the best model had AIC values similar to those of more complex models, we compared them by means of a likelihood ratio test. Thus, we ensured that adding a new variable to the best model did not increase the explained deviance. When more than one variable was included in the model, we quantified their relative contribution to the model with the help of the relimp package for $\mathrm{R}$. This method estimates the relative importance of two predictors in a glm model as the square root of the variance-ratio quantity denoted as "omega" in Silber et al. (1995). All statistical analyses were performed with R (R Development Core Team 2008). Means are shown with standard errors throughout the manuscript.

\section{Results \\ Patch characterization and phylogenetic distance calculations}

The distribution of phylogenetic distances between $N$. mezcalaensis and the nurse plant species across the 904 vegetation patches surveyed presented a contrasting pattern of both low (0-25 Myr) and high (248-322 Myr) phylogenetic distances (Fig. 1a). Low distances correspond to Cactaceae nurses, whereas high distances correspond to distantly related families such as Fabaceae, Anacardiaceae, Nolinaceae, and so forth. A similar picture was found regarding the phylogenetic distance of $N$. mezcalaensis to its nearest relative in the vegetation patch (Fig. 1b). The distribution of phylogenetic distances in our 31 experimental patches followed the same pattern. 

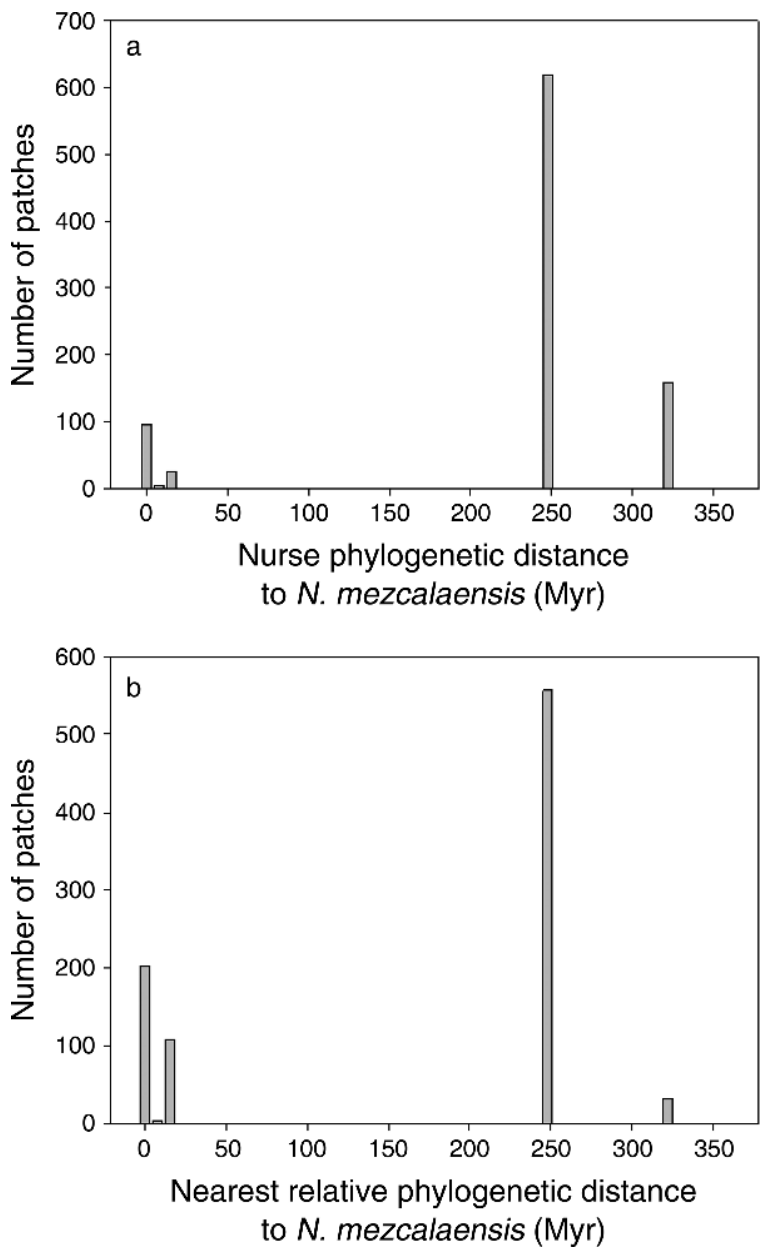

FIG. 1. Frequency distribution of the phylogenetic distances from the columnar cactus Neobuxbaumia mezcalaensis in Puebla, Mexico, with respect to (a) the dominant plant in the patch (nurse plant) and (b) its nearest relative in the patch; $N=$ 904 patches. Phylogenetic distances (PD) are in millions of years (Myr).

\section{Experiments of neighborhood effect on seedling establishment, survivorship, and growth}

Most shrub species inhabiting our 31 experimental vegetation patches were spatially associated with specific suites of other species (detailed descriptions of patch composition are in Appendix B); they averaged $3.84 \pm$ 0.41 species per patch (range $1-10$ species).

The number of emerged seedlings from the 50 seeds placed under the different treatments ranged from 2.66 \pm 1.20 to $29 \pm 3.16$ seedlings. The best model explaining seedling emergence had $\mathrm{PD}_{\text {nur }}$ alone (AICestab $=235.0$ in Table 1). The explained deviance of the model was not improved by including $\mathrm{PD}_{\text {rel }}$ (test deviance $=0.094 ; \mathrm{df}=$ $1, P=0.76)$ or $\mathrm{PD}_{\text {pat }}$ (test deviance $=0.002 ; \mathrm{df}=1, P=$ $0.97)$. The best model showed that seedling emergence was positively correlated with $\mathrm{PD}_{\text {nur }}$ (Table 2), indicating that the establishment probability of $N$. mezcalaensis increases with its phylogenetic distance to the nurse (Fig. 2). This relationship was clearly driven by the extremely low number of seedlings emerging under conspecific nurses, because the relationship became nonsignificant when these three points were removed from the analysis (estimate $\pm \mathrm{SE},-3.69 \pm 2.43 ; z=-1.52, P=0.13$ ). Three years after establishment, survivorship of the young plants ranged between $10 \% \pm 4 \%$ and $70 \% \pm 4 \%$ per patch. No phylogenetic distance measure explained this variation; the best model had the intercept alone $($ AICsurv $=119.2$ in Table 1, Table 2$)$ and the explained deviance was not enhanced after including $\mathrm{PD}_{\text {nur }}, \mathrm{PD}_{\text {rel }}$, and $\mathrm{PD}_{\text {pat }}$ (all the three test deviances had $P>0.2$ ).

The growth of $N$. mezcalaensis seedlings during the first three years ranged from $0.12 \pm 0.02 \mathrm{~cm}$ to $0.34 \pm$ $0.07 \mathrm{~cm}$, cumulative over three years, and the model that best explained the variation had $\mathrm{PD}_{\text {rel }}$ alone (AICgrow $=$ 128.9 in Table 1). The relationship between seedling growth and $\mathrm{PD}_{\text {rel }}$ was positive (Table 2), indicating that seedlings grow taller when they coexist with distant relatives in the patch. This relationship was not driven by conspecifics inhibiting seedling growth; in fact, the relationship became stronger when conspecific neigh-

TABLE 1. Model selection of variables influencing the magnitude of seedling establishment, survival, and growth, and survival of preestablished individuals of the columnar cactus Neobuxbaumia mezcalaensis.

\begin{tabular}{|c|c|c|c|c|}
\hline Variables in the model & AICestab & AICsurv & AICgrow $\dagger$ & AICsurv_pre \\
\hline Intercept $+\mathrm{PD}_{\text {nur }}+\mathrm{PD}_{\text {rel }}+\mathrm{PD}_{\text {pat }}$ & 238.9 & 123.4 & & 295.8 \\
\hline Intercept + PD $_{\text {nur }}+$ PD $_{\text {rel }}$ & 236.9 & 121.5 & & 316.3 \\
\hline Intercept $+\mathrm{PD}_{\text {nur }}$ & 235.0 & 119.7 & & 345.3 \\
\hline Intercept & 237.5 & 119.2 & 131.0 & 343.3 \\
\hline Intercept $+\mathrm{PD}_{\mathrm{rel}}$ & 237.1 & 120.2 & 128.9 & 323.2 \\
\hline Intercept $+\mathrm{PD}_{\text {pat }}$ & 237.6 & 119.8 & 132.4 & 296.0 \\
\hline Intercept $+\mathrm{PD}_{\text {nur }}+\mathrm{PD}_{\text {pat }}$ & 237.0 & 121.5 & & 294.7 \\
\hline Intercept $+\mathrm{PD}_{\text {rel }}+\mathrm{PD}_{\text {pat }}$ & 238.6 & 121.8 & 130.5 & 294.1 \\
\hline
\end{tabular}

Notes: The independent variables were the phylogenetic distance (PD) of $N$. mezcalaensis to its nurse plant ( $\left.\mathrm{PD}_{\text {nur }}\right)$, to its nearest relative $\left(\mathrm{PD}_{\text {rel }}\right)$, and to all its neighbors $\left(\mathrm{PD}_{\mathrm{pat}}\right)$ in the vegetation patch. Candidate models are shown with their relative $\mathrm{AICs}$ for seedling establishment (AICestab), survival (AICsurv), and growth (AICgrow) in experimental patches, as well as survival in the preestablished individuals (AICsurv_pre). The best models are highlighted in bold.

$\uparrow$ The models for seedling growth do not include $\mathrm{PD}_{\text {nur }}$ because the phylogenetic distance between the surviving $N$. mezcalaensis seedlings and the nurses did not vary among patches. 
TABLE 2. Best-fit models explaining the establishment, survival, and growth of $N$. mezcalaensis as a function of its phylogenetic distance to the nurse plant $\left(\mathrm{PD}_{\text {nur }}\right)$, to its nearest relative $\left(\mathrm{PD}_{\text {rel }}\right)$, and to all its neighbors in the patch $\left(\mathrm{PD}_{\text {pat }}\right)$.

\begin{tabular}{lrrr}
\hline \hline \multicolumn{1}{c}{ Demographic parameter } & Estimate & SE & $z$ \\
\hline Establishment in experimental patches & & & \\
$\quad$ Intercept & -1.82 & 0.62 & $-2.93^{* *}$ \\
PD $_{\text {nur }}$ & 0.23 & 0.12 & $2.00^{*}$ \\
Survival in experimental patches & & & \\
$\quad$ Intercept & -1.55 & 0.32 & $-4.82^{* *}$ \\
Growth in experimental patches & & & \\
$\quad$ Intercept & 2.48 & 0.28 & $8.75^{* *}$ \\
PD & 0.10 & 0.05 & $2.02^{*}$ \\
Survival of preestablished plants & & & \\
$\quad$ Intercept & -38.9 & 8.96 & $-4.33^{* *}$ \\
PD $_{\text {rel }}$ & -2.53 & 0.13 & $-1.95^{*}$ \\
PD $_{\text {pat }}$ & 7.25 & 1.74 & $4.25^{* *}$ \\
\hline
\end{tabular}

Note: Results of both seeded individuals in experimental patches and preestablished individuals are shown.

$* P \leq 0.05 ; * * P<0.01$.

bors were removed from the analysis (estimate $\pm \mathrm{SE}$, $0.24 \pm 0.08 ; t=3.09, P=0.002$; see inset in Fig. 3).

\section{Monitoring of survival and growth rates of young preestablished individuals}

The mean number of plant species that formed a patch was $2.43 \pm 0.09$ (range $1-5$ species). Mean threeyear survivorship of plants ranged from $10.69 \% \pm 5.43 \%$ to $75.52 \% \pm 3.4 \%$, and the best model explaining survivorship included both the phylogenetic distance to the nearest relative $\left(\mathrm{PD}_{\mathrm{rel}}\right)$ and the mean phylogenetic distance to all the neighbors in the patch $\left(\mathrm{PD}_{\mathrm{pat}}\right)$ (AICsurv pre $=294.1$ in Table 1). The explained deviance of this model was not improved after entering $\mathrm{PD}_{\text {nur }}$ in the model (test deviance $=0.34$, df $=1, P=$ 0.56). The best model showed that survival of the preestablished individuals was negatively affected by $\mathrm{PD}_{\text {rel }}$ but positively affected by $\mathrm{PD}_{\text {pat }}$ (Table 2). The relative contribution of $\mathrm{PD}_{\mathrm{pat}}$ to plant survival was eight times greater than that of $\mathrm{PD}_{\text {rel }}$ (ratio of effect standard deviations $=1.964 ;[3.6,18.4] 95 \%$ confidence interval) .

\section{DISCUSSION}

Our results indicate that evolutionary relationships among co-occurring species in vegetation clumps are significant predictors of the performance of experimentally planted $N$. mezcalaensis individuals in vegetation patches and thus predictors of the coexistence of this columnar cactus with other species. As a general pattern, we found that the greater the phylogenetic distance among neighbors, the greater was the performance of $N$. mezcalaensis. However, this general pattern is quite complex because different performance components of $N$. mezcalaensis were affected by phylogenetic relationships to the nurse, to the nearest relative, or to all the neighbors, depending on the life stage of $N$. mezcalaen- sis. These results provide, for the first time, novel empirical evidence for the direct and indirect positive effects of neighborhood phylodiversity on focal plants. Our results support the general facilitative processes elucidated through short-term and pairwise studies, but also provide a clear picture of the processes occurring during the ontogeny of the interaction in the context of true communities.

Long phylogenetic distances to the nurse species increase seedling establishment of $N$. mezcalaensis. This is mainly produced because of the low number of seedlings emerging under conspecific nurses and may explain why self-facilitation seldom occurs in this type of ecosystem (Valiente-Banuet and Verdú 2007, Verdú and Valiente-Banuet 2008). At the same time, this pattern is consistent with the findings that facilitation occurs between distantly related species and therefore increases community phylogenetic diversity, leading to an overdispersed community structure (Valiente-Banuet and Verdú 2007).

Once seedlings are established, we have found that survivorship is not affected in the short term (three years) by the phylogenetic distances of the focal plant to its nurse or to the rest of its neighbors. However, when looking at another performance component, growth, we found that growth rates in the first three years are positively correlated with the phylogenetic distance to the nearest relative, suggesting that closely related species within the patches begin to compete more strongly with focal plants. Thus, the effect of neighbors on focal plants was highly dependent on the variable used to estimate performance (see Gómez-Aparicio 2009).

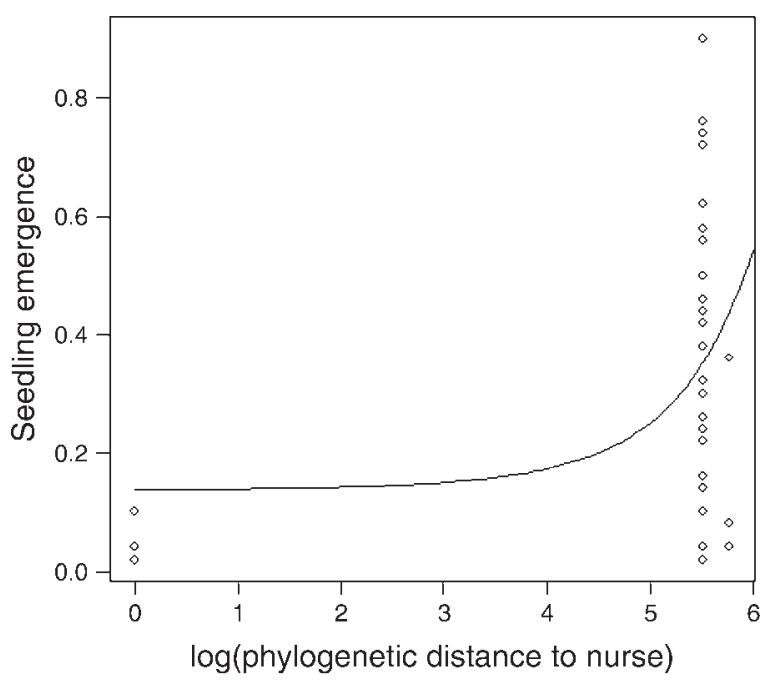

FIG. 2. Relationship between $N$. mezcalaensis seedling emergence (proportion of germinated seeds from each patch) and the log-transformed phylogenetic distance (originally measured in $\mathrm{Myr}$ ) to its nurse species ( $\left.\mathrm{PD}_{\text {nur }}\right)$ in the patch; $N$ $=31$ patches. 


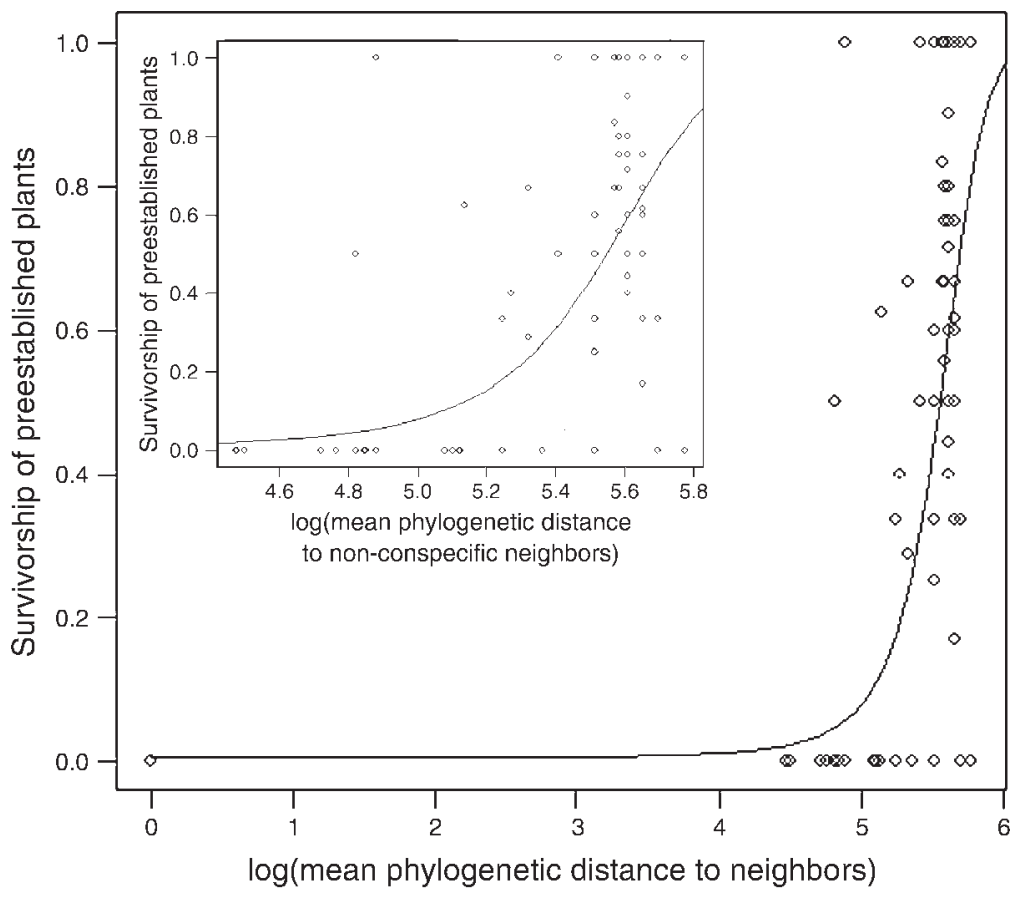

FIG. 3. Relationship between survivorship of preestablished (3-14 years old) individuals of $N$. mezcalaensis and the mean phylogenetic distance (originally measured in $\mathrm{Myr}$ ) to all its neighbors in the patch ( $\left.\mathrm{PD}_{\mathrm{pat}}\right) ; N=181$ patches. The inset graph shows the fit when conspecific neighbors are removed from the analysis.

The effect of neighbors also changed with time. Survivorship for plants between 3 and 14 years old was dependent on the phylogenetic distances to their nearest relatives $\left(\mathrm{PD}_{\mathrm{rel}}\right)$ and to all of the neighbors within a patch $\left(\mathrm{PD}_{\mathrm{pat}}\right)$. Surprisingly, $\mathrm{PD}_{\text {rel }}$ was negatively correlated with survival rates; this suggests that there is no tendency for plant species to compete more intensively with their close relatives, challenging a general interpretation of the competition-relatedness hypothesis (see Cahill et al. 2007). However, the relative contribution of $\mathrm{PD}_{\text {rel }}$ to the survivorship model was very low because survival was better explained by the interactions of the focal plant with all its neighbors $\left(\mathrm{PD}_{\text {pat }}\right)$, indicating that neighborhood phylodiversity exerts a very strong positive effect on survivorship of preestablished individuals. All of these results highlight the fact that the outcome of competition between pairs of species depends on the neighborhood phylodiversity; therefore paired interactions are not fully informing us about community-scale facilitation (Verdú and ValienteBanuet 2008).

If functional and ecological similarities are shaped by patterns of common ancestry, then distantly related species might be contributing to survivorship and coexistence patterns. Indeed, recent studies have indicated that phylogenetic unrelatedness is a good predictor of ecological differentiation (Prinzing et al. 2001, Wiens and Graham 2005) and, consequently, more distantly related species might reduce niche overlap, in turn reducing competition (Valiente-Banuet and Verdú
2008). As shown here, this prediction is useful for knowing which species is facilitated by which nurse successfully; it emphasizes the species-specific nature in facilitative relationships (Callaway 2007, Verdú and Valiente-Banuet 2008).

We have interpreted our results primarily in the context of phylogenetic effects on direct competition and facilitation among the plants. However, indirect interactions involving consumers with shared phylogenetic predilections may also explain our results. Recent research has shown that phylogenetically distant species can promote coexistence not only by reducing competition, but also by avoiding host-specific belowground enemies (Van der Putten 2009). Janzen (1970) and Connell (1971) first proposed such density-dependent effects of natural enemies beneath as effective mechanisms promoting species coexistence (also see Packer and Clay 2000, Reinhart et al. 2003). Thus pathogens may infect a set of more closely related hosts because barriers against pathogens are often phylogenetically conserved (Webb et al. 2006). Our data show that phylogenetic separation promotes species coexistence in the vegetation patches and future research should test at what extent such coexistence is mediated by pathogens.

In summary, we have found that species coexistence in vegetation patches is explained by a complex mixture of phylogenetically determined positive and negative interactions that vary over time. Positive effects on establishment mediated by distantly related nurses are preponderant early in the ontogeny of the interaction. 


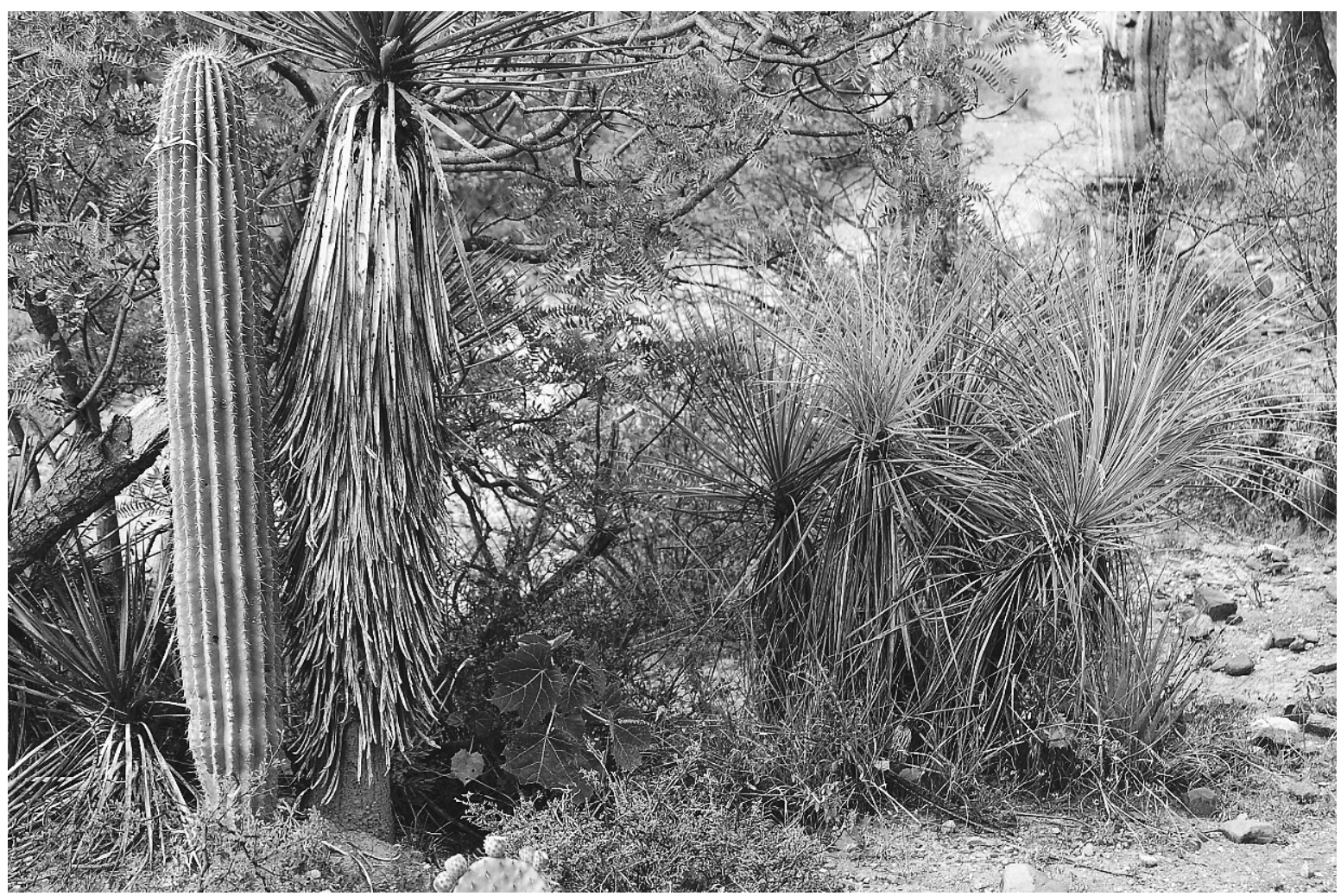

Plate 1. Vegetation patch composed of Neobuxbaumia mezcalaensis, Pseudosmodingium multifolium, Yucca periculosa, Cnidoscolus tehuacanensis, Bouteloua gracilis, Hechtia podantha, and Beaucarnea gracilis. Photo credit: A. Valiente-Banuet.

Competitive effects on growth mediated by the nearest relatives in a patch are the rule in the short term (1-3 years), and competitive effects of all the neighbors are the most relevant later. This changing scenario may explain why different studies, most of which had a duration of no more than two years, report contradictory results for ontogenetic shifts in plant interactions (Gómez-Aparicio 2009, Maestre et al. 2009). In conclusion, neighborhood phylodiversity exerts direct and indirect effects on plants, affecting individual performance and species coexistence.

\section{ACKNOWLEDGMENTS}

We thank Carlos Silva, J. Treviño, A. Flores, P. Estrella, A Vital, and L. Hernández for help with the experiments. R. M. Callaway and F. T. Maestre provided helpful comments on the manuscript. Financial support was provided by Dirección General de Asuntos del Personal Académico, UNAM (DGAPA-IN-224808-3), AECID (Project A/017475/08) and CYTED (Acción 409AC0369). J. P. Castillo was supported by a Ph.D. fellowship provided by CONACYT (Consejo Nacional de Ciencia y Tecnología, México; reg. 199649).

\section{Literature Cited}

Archer, S., C. Scifres, and C. R. Bassham. 1988. Autogenic succession in a subtropical savanna: conversion of grassland to thorn woodland. Ecological Monographs 58:111-127.

Bagchi, R., M. C. Press, and J. D. Scholes. 2010. Evolutionary history and distance dependence control survival of dipterocarp seedlings. Ecology Letters 13:51-59.
Bravo-Hollis, H. 1991. Las Cactáceas de México. Volume I. Universidad Nacional Autónoma de México, México.

Cahill, J. F., Jr., S. W. Kembel, E. G. Lamb, and P. A. Keddy. 2007. Does phylogenetic relatedness influence the strength of competition among vascular plants? Perspectives in Plant Ecology, Evolution and Systematics 10:41-50.

Callaway, R. M. 2007. Positive interactions and interdependence in plant communities. Sprinter-Verlag, Dordrecht, The Netherlands.

Callaway, R. M., et al. 2002. Positive interactions among alpine plants increase with stress. Nature 417:844-848.

Callaway, R. M., D. Kikodze, M. Chiboshvili, and L. Khetsuriani. 2005. Unpalatable plants protect neighbors from grazing and increase plant community diversity. Ecology 86:1856-1862.

Castillo, J. P., and A. Valiente-Banuet. 2010. Species-specificity of nurse plants for the establishment, survivorship, and growth of a columnar cactus. American Journal of Botany 97, in press.

Cavender-Bares, J., D. D. Ackerly, D. A. Baum, and F. A. Bazzaz. 2004. Phylogenetic overdispersion in Floridian oak communities. American Naturalist 163:823-843.

Cavender-Bares, J., K. H. Kozak, P. V. A. Fine, and S. W. Kembel. 2009. The merging of community ecology and phylogenetic biology. Ecology Letters 12:693-715.

Choler, P., R. Michalet, and R. M. Callaway. 2001. Facilitation and competition on gradients in alpine plant communities. Ecology 82:3295-3308.

Comita, L. S., and S. P. Hubbell. 2009. Local neighborhood and species' shade tolerance influence survival in a diverse seedling bank. Ecology 90:328-334.

Connell, J. H. 1971. On the role of natural enemies in preventing competitive exclusion in some marine animals 
and in rain forest trees. Pages 298-312 in P. J. Den Boer and G. Gradwell, editors. Dynamics in populations. PUDOC, Wageningen, The Netherlands.

Couteron, P., and K. Kokou. 1997. Woody vegetation spatial patterns in a semi-arid savanna of Burkina Faso, West Africa. Plant Ecology 132:211-227.

Dullinger, S., et al. 2007. Weak and variable relationships between environmental severity and small-scale co-occurrence in alpine plant communities. Journal of Ecology 95: 1284-1295.

Eccles, N. S., K. J. Esler, and R. M. Cowling. 1999. Spatial pattern analysis in Namaqualand desert plant communities: evidence for general positive interactions. Plant Ecology 142: $71-85$.

Emerson, B. C., and R. G. Gillespie. 2008. Phylogenetic analysis of community assembly and structure over space and time. Trends in Ecology and Evolution 23:619-630.

Goldberg, D. E., R. Turkington, L. Olsvig-Whittaker, and A. R. Dyer. 2001. Density dependence in an annual plant community: variation among life history stages. Ecology 71: 423-446.

Gómez-Aparicio, L. 2009. The role of plant interactions in the restoration of degraded ecosystems: a meta analysis across life-forms and ecosystems. Journal of Ecology 97:1202-1214.

Janzen, D. H. 1970. Herbivores and the number of tree species in tropical forests. American Naturalist 104:501-508.

Maestre, F. T., R. M. Callaway, F. Valladares, and C. J. Lortie. 2009. Refining the stress-gradient hypothesis for competition and facilitation in plant communities. Journal of Ecology 97: 199-205.

Maestre, F. T., C. Escolar, I. Martínez, and A. Escudero. 2008. Are soil lichen communities structured by biotic interactions? A null model analysis. Journal of Vegetation Science 19:261266.

Packer, A., and K. Clay. 2000. Soil pathogens and spatial patterns of seedling mortality in a temperate tree. Science 404:278-281.

Prentice, I. C., and M. J. A. Werger. 1985. Clump spacing in a desert dwarf shrub community. Vegetatio 63:133-139.

Prinzing, A., W. Durka, S. Klotz, and R. Brandl. 2001. The niche of higher plants: evidence for phylogenetic conservatism. Proceedings of the Royal Society B 268:2383-2389.

R Development Core Team. 2008. R: A language and environment for statistical computing. R Foundation for Statistical Computing, Vienna, Austria. 〈http://www. R-project.org $\rangle$

Reinhart, K. O., A. Packer, W. H. van der Putten, and K. Clay. 2003. Plant-soil biota interactions and spatial distribution of black cherry in its native and invasive ranges. Ecology Letters 6:1046-1050.

Silber, J. H., P. R. Rosenbaum, and R. N. Ross. 1995. Comparing the contributions of groups of predictors: which outcomes vary with hospital rather than patient characteristics? Journal of the American Statistical Association 90:718.

Stevens, P. F. 2005. Angiosperm phylogeny website. Version 6. $\langle$ http://www.mobot.org/MOBOT/research/APweb/〉

Valiente-Banuet, A., A. Casas, A. Alcántara, P. Dávila, N. Flores-Hernández, M. Arizmendi, J. Villaseñor, and J. Ortega. 2000. La vegetación del Valle de Tehuacán-Cuicatlán. Boletin de la Socieda Botanica de México 67:24-74.

Valiente-Banuet, A., A. Rojas-Martínez, M. Arizmendi, and P. Dávila. 1997. Pollination biology of two columnar cacti (Neobuxbaumia mezcalaensis and Neobuxbaumia macrocephala) in the Tehuacán Valley, Central México. American Journal of Botany 84:452-455.

Valiente-Banuet, A., and M. Verdú. 2007. Facilitation can increase the phylogenetic diversity of plant communities. Ecology Letters 10:1029-1036.

Valiente-Banuet, A., and M. Verdú. 2008. Temporal shifts from facilitation to competition occur between closely related taxa. Journal of Ecology 96:489-494.

Van der Putten, W. H. 2009. A multitrophic perspective on functioning and evolution of facilitation in plant communities. Journal of Ecology 97:1131-1138.

Verdú, M., P. J. Rey, J. M. Alcántara, G. Siles, and A. Valiente-Banuet. 2009. Phylogenetic signatures of facilitation and competition in successional communities. Journal of Ecology 97:1171-1180.

Verdú, M., and A. Valiente-Banuet. 2008. The nested assembly of plant facilitation networks prevents species extinctions. American Naturalist 172:751-760.

Webb, C. O. 2000. Exploring the phylogenetic structure of ecological communities: an example for rain forest trees. American Naturalist 156:145-155.

Webb, C. O., D. D. Ackerly, and S. W. Kembel. 2008. Phylocom: software for the analysis of phylogenetic community structure and trait evolution. Bioinformatics 24:20982100 .

Webb, C. O., D. D. Ackerly, M. A. McPeek, and M. J. Donoghue. 2002. Phylogenies and community ecology. Annual Review of Ecology, Evolution, and Systematics 33: 475-505.

Webb, C. O., G. S. Gilbert, and M. J. Donoghue. 2006. Phylodiversity-dependent seedling mortality, size structure, and disease in a Bornean rain forest. Ecology 87(Supplement):S123-S131.

Wiens, J. J., and C. H. Graham. 2005. Niche conservatism: integrating evolution, ecology, and conservation biology. Annual Review of Ecology, Evolution, and Systematics 36: 519-539.

Wikstrom, N., V. Savolainen, and M. W. Chase. 2001. Evolution of the angiosperms: calibrating the family tree. Proceedings of the Royal Society B 268:2211-2220.

\section{APPENDIX A}

Photographs of vegetation patches (Ecological Archives E091-256-A1).

\section{APPENDIX B}

List of experimental vegetation patches where Neobuxbaumia mezcalaensis performance was evaluated (Ecological Archives E091-256-A2). 